Extended Continuous beta-Lactam Infusion With Oral Acetaminophen in Childhood Bacterial Meningitis : A( )Randomized, Double-blind Clinical Trial

\title{
Savonius, Okko
}

2021-05-15

Savonius, O, Rugemalira , E , Roine , I , Leite Cruzeiro , M , Peltola , H \& Pelkonen , T 2021 , ' Extended Continuous beta-Lactam Infusion With Oral Acetaminophen in Childhood Bacterial Meningitis : A( )Randomized, Double-blind Clinical Trial ', Clinical Infectious Diseases , vol. 72 , no. 10 , pp. 1738-1744 . https://doi.org/10.1093/cid/ciaa341

http://hdl.handle.net/10138/333089

https://doi.org/10.1093/cid/ciaa341

acceptedVersion

Downloaded from Helda, University of Helsinki institutional repository.

This is an electronic reprint of the original article.

This reprint may differ from the original in pagination and typographic detail.

Please cite the original version. 


\section{Extended Continuous $\beta$-Lactam Infusion with Oral Acetaminophen in Childhood Bacterial Meningitis: A Randomized, Double-Blind Clinical Trial}

Okko Savonius, M.D. ${ }^{a}$, Emilie Rugemalira, M.D. ${ }^{a}$, Irmeli Roine, M.D., Ph.D. ${ }^{b}$, Manuel Leite Cruzeiro, M.D. ${ }^{c}$, Heikki Peltola, M.D., Ph.D. ${ }^{a}$, and Tuula Pelkonen, M.D., Ph.D. ${ }^{a, c}$

${ }^{a}$ Children's Hospital, Pediatric Research Center, University of Helsinki, Helsinki University Hospital, Helsinki, Finland

${ }^{b}$ Faculty of Medicine, University Diego Portales, Santiago, Chile

${ }^{c}$ Hospital Pediátrico David Bernardino, Luanda, Angola

Corresponding author: Okko Savonius, Children's Hospital, Pediatric Research Center, University of Helsinki, Helsinki University Hospital, Helsinki, Finland; Stenbäckinkatu 9, 00290 Helsinki; Email: okko.savonius@helsinki.fi; Tel: +358-45-673-1185; Fax.+358-9-471-75315. 
Summary: A continuous $\beta$-Lactam infusion combined with high-dose oral paracetamol did not improve the prognosis of childhood bacterial meningitis in Angola, while compared to conventional treatment. Our results underline the dismal outcomes of bacterial meningitis in these settings. 


\section{ABSTRACT}

\section{Background}

In our previous study in Luanda, Angola, initial continuous $\beta$-lactam infusion for 24 hours combined with oral acetaminophen for 48 hours showed promising results as a new treatment for childhood bacterial meningitis. We investigated whether extending this treatment regimen to 4 days would improve the outcomes further.

\section{Methods}

We conducted a randomized, double-blind, parallel-group study at the same hospital in Luanda. Children aged 2 months to 15 years presenting to hospital with symptoms and signs of bacterial meningitis were randomized to receive, for the first 4 days, a continuous infusion of cefotaxime $(250 \mathrm{mg} / \mathrm{kg} /$ day) with simultaneous oral acetaminophen (first dose $30 \mathrm{mg} / \mathrm{kg}$, then $20 \mathrm{mg} / \mathrm{kg}$ every 6 hours), or cefotaxime conventionally as boluses $(62.5 \mathrm{mg} / \mathrm{kg}, 4$ times per day) with placebo orally. All children received also glycerol orally. The primary outcome was mortality by day 7 .

\section{Results}

In all, 375 patients were included in the study between January 22, 2012 and January 21, 2017. As two children succumbed before treatment initiation, 187 vs. 186 participants remained in the intervention and control groups, respectively. On day 7, 61/187 (32.6\%) children in the intervention group versus $64 / 186$ (34.4\%) in the control group had died (risk ratio $0.95,95 \%$ confidence interval 
[95\% Cl] $0.71-1.26$; absolute risk difference $1.8 \%, 95 \% \mathrm{Cl}-7.8-11.4)$. At discharge from hospital, the corresponding numbers were $71 / 187$ (38.0\%) and 75/186 (40.3\%).

\section{Conclusions}

Prolonged continuous $\beta$-lactam infusion combined with oral acetaminophen did not improve the gloomy outcomes of childhood bacterial meningitis in Angola.

Keywords: bacterial meningitis, continuous infusion, acetaminophen, paracetamol, children

(ClinicalTrials.gov, NCT01540838) 


\section{INTRODUCTION}

Bacterial meningitis (BM) remains a serious threat to global child health, being the $10^{\text {th }}$ most common cause of death in children under 5 years old [1]. The disease burden falls in particular on children in resource-poor settings, where the mortality rates may still rise up to $50 \%$, survivors being often left with disabling neurological or audiological sequelae. Although vaccination against Haemophilus influenzae type b (Hib), several types of Streptococcus pneumoniae, and the essential serogroups of Neisseria meningitidis have reduced the burden [2-4], the poor disease outcomes urgently call for more effective treatment modalities.

Dexamethasone, and to a lesser extent, glycerol have been evaluated as adjunctive treatments for childhood BM. The results have been controversial [5-8], as their effects likely relate to the study environment, causative bacteria, patient age, and likely most importantly, to the clinical condition on admission [9]. Neither treatment has, however, significantly reduced the high mortality rate of this potentially devastating disease. This said, oral glycerol prevented severe neurological sequelae in a large $(N=654)$ randomized placebo-controlled study in Latin America, the odds ratio (OR) for glycerol being 0.31 (95\% confidence interval [CI] 0.13-0.76) compared to the placebo recipients [7]. Although a similar effect was not obtained later in a smaller study in Malawi [8], the clear results from Latin America prevented us, for ethical grounds, from withdrawal of the utilization of glycerol in our further BM studies in Africa.

As $\beta$-lactam antibiotics exert time-dependent killing of bacteria, prolonged or continuous infusions may optimize the pharmacodynamic performance of these compounds [10]. A continuous infusion may also produce other benefits, such as a better controlled inflammatory response due to less fluctuating target antibiotic concentrations. We therefore performed a randomized, double-blind, and placebo-controlled study at the Hospital Pediátrico David Bernardino in Luanda, Angola in 20052008, in which the effects of initial continuous infusion of cefotaxime were examined [11]. In addition, large-dose oral acetaminophen (paracetamol) was administered, the basis for this 
intervention deriving from a large retrospective analysis of bacteremic adult patients in Finland [12]. Our main finding from this series of 723 BM patients was that the children receiving cefotaxime infusion for 24 hours and oral acetaminophen for 48 hours showed significantly lower mortality, this effect starting within the first 24 hours from treatment initiation and lasting for several days [11]. Although there was insufficient evidence of a difference at discharge from hospital, this encouraging result prompted us to examine our finding further in another study.

With this background a new trial was carried out at the same institution in Angola, now with a prolongation of our modified treatment. We here report the results of this particular investigation.

\section{METHODS}

\section{Study Design and Participants}

This was a single-center, randomized, double-blind, placebo-controlled parallel-group study conducted at the Hospital Pediátrico David Bernardino in Luanda, Angola. With its 300 beds and 250 daily attendees of whom 70 are hospitalised, the institute is the largest pediatric referral center and teaching hospital in Angola. The ethics committee of the hospital approved the study protocol on 19.1.2012.

The study entry was assessed for all children aged 2 months to 15 years presenting with the symptoms and signs suggestive of BM to whom lumbar puncture was performed. The child was enrolled, if the cerebrospinal fluid (CSF) appeared cloudy, was positive by Gram staining or showed at least 50 leukocytes per $\mathrm{mm}^{3}$. Exclusion criteria included previous known neurological abnormalities or hearing impairment, immunosuppression except for HIV infection, active tuberculosis, known hepatic disease, or pre-treatment with more than one dose of parenteral antibiotic. Before enrolment, the attending physician explained the study to the child's legal 
guardian, whose consent was expressed by a signature or, in case of illiteracy, a finger print. If participation was refused, the child was treated as routinely in the hospital.

The intention-to-treat population comprised all enrolled children, excluding the patients who succumbed before the initiation of treatment. The per-protocol analysis included the patients who received the allocated treatment and had confirmed BM, defined as a positive CSF culture or PCR; those with compatible symptoms and signs of BM and a positive blood culture; or the children with compatible symptoms and at least two of the following criteria: CSF pleocytosis $\geq 100$ cells $/ \mathrm{mm} 3$ (predominantly polymorphs), a positive CSF Gram stain result, a positive CSF latex agglutination test, or serum C-reactive protein (CRP) level $\geq 40 \mathrm{mg} / \mathrm{L}$.

Basic laboratory analyses, bacterial cultures and sensitivity tests were performed at the hospital's laboratory with standard techniques. As of October 2016, CSF samples were also sent to the National Institute for Communicable Diseases in Johannesburg, South Africa, for identification of $N$. meningitidis, S. pneumoniae and H.influenzae by PCR [13].

\section{Randomization and Masking}

Randomization was done using a computer generated list in fixed blocks of 20 which allocated the participants in a 1:1 ratio. The code was kept in a sealed envelope in the office of the head of the hospital, and a copy was sent to the external Data Safety Monitoring Board for the interim analyses. For emergency purposes, the opening key was kept sealed also in Helsinki.

The cards disclosing the specific treatment were kept in sealed envelopes in a box at the hospital ward. Once the attending physician had included a patient in the study, an otherwise nonparticipating study nurse opened the next envelope, prepared the medications and placebos as advised, and gave the preparations for 96 hours (4 days). Thus, the patients, guardians, attending physicians and the investigators were kept blinded to the intervention. 
For further masking, all children received both infusions and boluses intravenously for the entire 4day course. Since the ready-to-use cefotaxime is slightly yellowish liquid, yellow i.v. lines (BectonDickinson GmbH, Art.No. 300326) and black 50 ml syringes (B Braun, Ref No 8728828F) were used with a foil covering on the 3-way stopcock's (B Braun Smallbore T-Port Extension Set, Ref No 471954) short end which leads to the skin-penetrating needle. This setup allowed the same one line for the antimicrobial and placebo administrations, each always given as infusion or boluses.

As black syringes and yellow i.v. lines were used, saline could be used as a placebo preparation for cefotaxime, no matter how administered. The oral acetaminophen solution from effervescent tablets looked like plain water once the bubbles had disappeared. Being practically tasteless, regular drinking water served as its placebo.

\section{Procedures}

All children were treated with cefotaxime in a dose of $250 \mathrm{mg} / \mathrm{kg} / 24$ hours for seven days. For the first four days, the children were randomized to receive the agent as a continuous intravenous infusion with high-dose acetaminophen orally (first dose $30 \mathrm{mg} / \mathrm{kg}$, then $20 \mathrm{mg} / \mathrm{kg}$ every 6 hours for 4 full days), or as conventional intravenous boluses ( $62.5 \mathrm{mg} / \mathrm{kg}$ every 6 hours) with placebo orally. To prevent degradation of the antibiotic, the daily dose of cefotaxime was administered as two 12hour infusions $\left(125 \mathrm{mg} / \mathrm{kg}\right.$ each). The dissolved acetaminophen (Panadol ${ }^{\circledR}$ ) tablets formed a solution with $10 \mathrm{mg} / \mathrm{ml}$ of acetaminophen.

Based on our previous studies $[7,11]$, all children were given oral glycerol $(6.0 \mathrm{~g} / \mathrm{kg}$ per day divided into 4 equal doses, maximum dose of $25 \mathrm{~g}$ ) for 2 days. Antipyretics (besides scheduled acetaminophen as part of the intervention) were avoided. If hyperpyrexia or pain required medication, ibuprofen was given at a dose of $15 \mathrm{mg} / \mathrm{kg}$ twice daily. Seizures were treated as was the routine in the hospital, most commonly with diazepam, while for malaria, quinine and artemisine 
derivatives were used. A blood transfusion $(10 \mathrm{ml} / \mathrm{kg})$ was administered to children with a haemoglobin level $<50 \mathrm{~g} / \mathrm{L}$, and sometimes also if considered clinically relevant. Fluid therapy aimed at normovolemia. Blood glucose was monitored four times daily, and hypoglycaemia was corrected with intravenous $10 \%$ glucose solution. All treatments were recorded in the specifically designed follow-up sheets.

\section{Outcomes}

The primary outcome measure was mortality by day seven in hospital. The secondary outcome measures included later in-hospital mortality, the composite outcomes of death or severe neurological sequelae (hydrocephalus, severe psychomotor retardation, quadriparesis, or blindness), and death or any neurological sequelae (hemi- or monoparesis, ataxia, or psychomotor retardation of any degree, besides the above-mentioned sequelae). The secondary neurological outcomes were recorded on day seven and at discharge from hospital.

We also aimed at measuring the hearing impairment quantitatively, but due to economical and practical constraints, precise audiological measurements were eventually performed only in a handful of survivors. Adverse events and the safety of our treatment were assessed as part of the detailed follow-up of all participants.

\section{Statistical Analysis}

Based on our previous study in Angola [11], we assumed to attain a 13\% decrease in mortality with our intervention in patients with confirmed BM. Accepting a 5\% error after adjustment for multiple testing in one-tailed test with a power of $80 \%$, at least 165 patients were required in each treatment group. Because of several confounding factors, such as dissimilar age, severity on admission, 
malnutrition and malaria, we intended to enrol 400 patients. An external Data Safety Monitoring Board obtained the 7-day results after each 100 patients had been evaluated. Had an indisputable significance between the treatment modalities been found, the board would have interrupted enrolment for ethical reasons.

Differences between the study groups regarding the in-hospital clinical course were assessed using chi-square test or Mann-Whitney U test, as appropriate. Potential differences between the study groups in terms of the primary and secondary outcomes were analysed by chi-square test, or in the case of low expected cell values in the $2 \times 2$ table, Fisher's exact test. The treatment effects on the primary and secondary outcomes were presented as risk ratios with $95 \%$ confidence intervals (Cl); the absolute risk difference and its confidence intervals were obtained using a 2-sample z-test. Kaplan-Meier analysis and the log-rank test were used when comparing the time of death and potential differences in survival, while treatment interactions between subgroups were examined with logistic regression analysis. All subgroup analyses were predefined in the study protocol. Pvalues $<0.05$ were considered statistically significant, and to detect potential adverse effects of the treatments, all analyses were conducted using a two-sided hypothesis. Furthermore, differences between the participants of the current study and our previous trial in Luanda were assessed using chi-square test or Mann-Whitney U test.

\section{RESULTS}

Recently commenced Hib and pneumococcal vaccinations in Angola had reduced the incidence of $\mathrm{BM}$ to the extent that patient enrolment was extended to the predefined maximum of five years (from January 22, 2012 to January 21, 2017). In all, 1128 children were assessed for eligibility, 753 were excluded, and 375 children were randomized into the treatment groups. Since two patients 
succumbed before treatment initiation, 373 children comprised the intention-to-treat population (Figure 1).

Of those, 43 were protocol violators: in 16 cases paralytic ileus prevented oral administration, while the remaining 27 treatment failures were due to insurmountable practical difficulties such as dysfunctional intravenous lines. The number of treatment failures was similar in both treatment arms (Figure 1). Finally, our strict criteria for confirmed BM excluded additional 126 participants from the per-protocol population which ultimately comprised 204 children (Figure 1).

As summarized in Table 1, the patient characteristics and laboratory results proved similar in both groups. Since the median prehospital duration of illness was five days, the child was usually severely ill: $67 \%$ had suffered from seizures and some $1 / 3$ showed focal neurological signs on admission. Malnutrition was common, and according to the WHO reference [14], 26\% of the children presented with a weight-for-age Z-score under -2 SD. The causative agent was identified in 152/373 (41\%) of cases, S. pneumoniae being the most common bacterium (Table 1). Interestingly, other not-socommon agents such as Klebsiella spp. $(\mathrm{n}=6)$ and Proteus spp. $(\mathrm{n}=6)$ were also detected.

After 7 days of treatment, 125 (34\%) of the 373 patients had died. The composite outcomes of death or severe neurological sequelae (SeNeSe), and of death or any neurological sequelae (AnNeSe) were observed in 45\% (155/345) and 54\% (182/334) of the series, respectively (Table 2). As 21 patients succumbed after the first week, the final fatality rate increased to $39 \%$. At discharge, $47 \%(175 / 369)$ of patients had either died or survived with severe neurological sequelae. Adding any neurological sequelae to the calculation, the proportion rose to $54 \%$ (193/360) (Table 2).

The day-7 mortality and the death rate at discharge were similar in the treatment groups (Table 2). Nor did their composite outcomes differ, albeit the effect of the interventional treatment seemed somewhat more consistent (all risk ratios staying below one) in the per-protocol population (Table 
2). Overall, our prolonged modified treatment did not show significant benefits, as depicted in Figure 2.

Since the prognosis of BM differs substantially in different populations, we also analysed certain predefined subgroups (Table 3). While the overall mortality varied largely, the given treatment did not relate to improved survival in any subgroup. Regarding the course of illness on the ward, ibuprofen was given more often in the control group, likely due to the higher need of antipyresis among these children (Table 4).

Potential adverse events of the treatments were registered as part of the normal follow-up. Furthermore, any abnormal signs of illness, not compatible with the diagnosis of meningitis, were registered in the follow-up sheet. In this regard, the groups did not differ.

\section{DISCUSSION}

No benefit from using prolonged four-day infusion of cefotaxime combined with oral acetaminophen was found in this trial on childhood BM in Luanda, Angola. Mortality and neurological sequelae remained the same regardless of whether cefotaxime with or without oral acetaminophen was administered conventionally in boluses every 6 hours, or as continuous infusion for four days.

Our rationale for using continuous infusion of antibiotic in BM relies, in addition to the pharmacodynamic advantages, also on relieving the initial inflammatory burst triggered by the strongly bacteriolytic $\beta$-lactam in the central nervous system. The basis for using oral acetaminophen at the same time laid, on the other hand, in the large retrospective study in which it significantly associated with decreased mortality in adult bacteraemia [12]. In our previous trial in Angola [11], an initial 24-hour cefotaxime infusion with the simultaneous 48-hour oral acetaminophen reduced BM mortality in children for several days - this effect being finally lost at discharge from hospital. It was 
thus logic to assume that prolonging our modified treatment would lead to permanent mortality decrease. As disappointing as it was, this was not the case here: no benefit was achieved with such a treatment prolongation.

To find explanations for this discrepancy, we searched for differences between these two patient populations (Supplementary Table 1 in Supplementary Material). Shortly, participants in this study arrived to hospital more severely ill, were more frequently malnourished and dehydrated, and clearly differed in etiology. The role of Hib meningitis was dramatically reduced while the proportion of less common meningitis agents increased, and more participants were left with an unknown bacterial etiology. The participants of this study were also older and had received pre-admission antibiotics more often, while compared to the participants of our previous trial.

Our interpretation is that many children here had already passed the moment when the new treatment would have had a potential to help the patient [15]. Of special note is our earlier finding that in childhood BM, the presenting condition surpasses all other cofactors predicting death, being as a single covariant even more important than the causative agent as such [9]. The major changes in bacterial etiology might also contribute to the discrepancy between our two trials.

Some correlation to the adult studies, in which continuous or prolonged antibiotic infusions have also led to non-consistent results, might here be justifiably drawn [16]. Slow, continuous infusion probably performs best in some patient subpopulations whose identification poses a challenge to future trials.

Successful Hib and pneumococcal vaccinations in Angola hindered our collection of the targeted minimum of 165 confirmed BM cases in both study groups. The large heterogeneous group, which was excluded from the per-protocol analysis, comprised children with diseases such as tuberculous meningitis, cerebral malaria and rabies - and among them there probably were some cases of partially treated BM as well. A major limitation was also the lack of adequate audiological 
measurements in survivors, which prevented us from evaluating the treatment's possible effect on hearing impairment.

All these shortcomings no doubt lessened the value of our observations. This said, however, our experience is a truthful description of the circumstances prevailing today in many sites of subSaharan Africa. Acknowledging the frequent lack of diagnostic tools and the challenging differential diagnostics, our intention-to-treat population probably well represents children who are treated for BM in these settings. Therefore, in spite of the large drop-out rate, we believe our main result remains valid and applicable for this kind of patient populations.

Our study underlines the gloomy prognosis of childhood BM in Angola. A continuous antibiotic infusion and oral acetaminophen did not improve the outcome of these severely ill children, who often came late for treatment. Since the prehospital delay is unbearably long, more efforts should be put into the parents' knowledge of the symptoms and signs of BM. Also better availability of healthcare would hasten the adequate treatment. Large-scale vaccinations against the relevant agents are good servants when combating this devastating disease. 
NOTES

\section{Acknowledgements}

We thank the external Data Safety Monitoring Board for performing the interim safety analyses, and Matti Kataja and Paula Bergman for skilful statistical consulting. Furthermore, we thank Orion Diagnostica for providing reagents for the measurements of C-reactive protein. Finally, we thank our colleagues at Hospital Pediátrico David Bernardino for excellent collaboration, and all the involved children and their families in Luanda for participating in this trial.

\section{Funding}

This work was supported by the Pediatric Research Foundation; Päivikki and Sakari Sohlberg's foundation; Sigrid Jusélius Foundation; Finska Läkaresällskapet; Stiftelsen Dorothea Olivia, Karl Walter och Jarl Walter Perkléns minne; and the Orion Research Foundation. T.P. reports grants from Lastentautien Tutkimussäätiö.

\section{Potential conflicts of interest}

T.P. has received research funding from Sanofi Pasteur (Lyon, France). All the other authors report no potential conflicts of interest. 


\section{REFERENCES}

1. GBD 2015 Child Mortality Collaborators. Global, regional, national, and selected subnational levels of stillbirths, neonatal, infant, and under-5 mortality, 1980-2015: A systematic analysis for the global burden of disease study 2015. Lancet 2016; 388:1725-74.

2. Peltola H, Pelkonen T, Bernardino L, et al. Vaccine-induced waning of haemophilus influenzae empyema and meningitis, Angola. Emerg Infect Dis 2014; 20:1887-90.

3. Ouldali N, Levy C, Varon E, et al. Incidence of paediatric pneumococcal meningitis and emergence of new serotypes: A time-series analysis of a 16-year french national survey. Lancet Infect Dis 2018; 18:983-91.

4. Trotter $\mathrm{CL}$, Lingani $\mathrm{C}$, Fernandez $\mathrm{K}$, et al. Impact of MenAfriVac in nine countries of the African meningitis belt, 2010-15: An analysis of surveillance data. Lancet Infect Dis 2017; 17:867-72.

5. Brouwer MC, McIntyre P, Prasad K, van de Beek D. Corticosteroids for acute bacterial meningitis. Cochrane Database Syst Rev 2015; CD004405.

6. Wall EC, Ajdukiewicz KM, Bergman H, Heyderman RS, Garner P. Osmotic therapies added to antibiotics for acute bacterial meningitis. Cochrane Database Syst Rev 2018; CD008806.

7. Peltola H, Roine I, Fernandez J, et al. Adjuvant glycerol and/or dexamethasone to improve the outcomes of childhood bacterial meningitis: A prospective, randomized, double-blind, placebocontrolled trial. Clin Infect Dis 2007; 45:1277-86.

8. Molyneux EM, Kawaza K, Phiri A, et al. Glycerol and acetaminophen as adjuvant therapy did not affect the outcome of bacterial meningitis in Malawian children. Pediatr Infect Dis J 2014; 33:214-6.

9. Roine I, Peltola H, Fernández J, et al. Influence of admission findings on death and neurological outcome from childhood bacterial meningitis. Clin Infect Dis 2008; 46:1248-52. 
10. Craig WA. Pharmacokinetic/pharmacodynamic parameters: Rationale for antibacterial dosing of mice and men. Clin Infect Dis 1998; 26:1-12.

11. Pelkonen T, Roine I, Cruzeiro ML, Pitkaranta A, Kataja M, Peltola H. Slow initial beta-lactam infusion and oral paracetamol to treat childhood bacterial meningitis: A randomised, controlled trial. Lancet Infect Dis 2011; 11:613-21.

12. Kuikka A, Sivonen A, Emelianova A, Valtonen VV. Prognostic factors associated with improved outcome of escherichia coli bacteremia in a Finnish university hospital. Eur J Clin Microbiol Infect Dis 1997; 16:125-34.

13. Wang X, Theodore MJ, Mair R, et al. Clinical validation of multiplex real-time PCR assays for detection of bacterial meningitis pathogens. J Clin Microbiol 2012; 50:702-8.

14. WHO Multicentre Growth Reference Study Group. WHO child growth standards. Length, height for-age, weight-for-age, weight-for-length and body mass index-for age. Methods and development. World Health Organization 2006. Available at:

http://www.who.int/childgrowth/standards/Technical_report.pdf. Accessed 25 August 2018.

15. Nau R, Djukic M, Spreer A, Ribes S, Eiffert H. Bacterial meningitis: An update of new treatment options. Expert Rev Anti Infect Ther 2015; 13:1401-23.

16. Vardakas KZ, Voulgaris GL, Maliaros A, Samonis G, Falagas ME. Prolonged versus short-term intravenous infusion of antipseudomonal beta-lactams for patients with sepsis: A systematic review and meta-analysis of randomised trials. Lancet Infect Dis 2018; 18:108-20. 


\section{TABLES}

Table 1. Baseline patient characteristics of the intention-to-treat population

\begin{tabular}{|c|c|c|}
\hline Characteristic & $\begin{array}{l}\text { Bolus + placebo } \\
\qquad(N=186)\end{array}$ & $\begin{array}{l}\text { Infusion + acetaminophen } \\
\qquad(\mathrm{N}=187)\end{array}$ \\
\hline Age in months (range) & $31(1-161)$ & $28(2-177)$ \\
\hline Male sex & $115(62 \%)$ & $101(54 \%)$ \\
\hline Weight-for-age under $-2 S^{a}$ & $48 / 185(26 \%)$ & 48 / $186(26 \%)$ \\
\hline Duration of symptoms $>3$ days ${ }^{a}$ & 116 / 181 (64\%) & $136 / 184$ (74\%) \\
\hline Previous antibiotics $^{a}$ & 73 / 165 (44\%) & 95 / 170 (56\%) \\
\hline Seizures before admission ${ }^{a}$ & 122 / 175 (70\%) & $116 / 178(65 \%)$ \\
\hline Glasgow Coma Scale score & $11(8-15)$ & $12(9-15)$ \\
\hline Focal neurological signs ${ }^{a}$ & 53 / $181(29 \%)$ & 60 / $176(34 \%)$ \\
\hline Another focus of infection ${ }^{a}$ & 46 / $169(27 \%)$ & 62 / $178(35 \%)$ \\
\hline Dyspnoea $^{a}$ & 111 / 177 (63\%) & $100 / 181(55 \%)$ \\
\hline Dehydration $^{a}$ & $43 / 183(23 \%)$ & $46 / 182(25 \%)$ \\
\hline \multicolumn{3}{|l|}{ Blood test results: } \\
\hline $\mathrm{Hb}(\mathrm{g} / \mathrm{L})^{\mathrm{b}}$ & $73(60-92)$ & $74(62-89)$ \\
\hline Leukocyte count $\left(\times 10^{9} / \mathrm{L}\right)^{b}$ & $15.1(9.0-21.0)$ & $13.7(8.8-19.7)$ \\
\hline $\mathrm{CRP}(\mathrm{mg} / \mathrm{L})^{\mathrm{b}}$ & $160(96->160)$ & $160(91->160)$ \\
\hline Malaria test positive $^{c}$ & $51 / 186(27 \%)$ & 40 / 187 (21\%) \\
\hline HIV test positive & 4 / 98 (4\%) & 11 / 93 (12\%) \\
\hline
\end{tabular}


CSF test results:

Leukocyte count (x 10\%/L)

Protein level (mg/dL)

Glucose level (mmol/L)

Causative agent

Streptococcus pneumoniae $(n=73)$

Neisseria meningitidis $(\mathrm{n}=37)$

Haemophilus influenzae $(n=7)$

Other bacteria $(n=39)$

Unknown (n=217)
495 (130-2770)

800 (140-2289)

197 (123-265)

187 (110-250)

$0.9(0.5-2.7)$

$1.1(0.5-2.4)$ 


\section{Table 2. The two treatment modalities versus the risk of adverse outcomes in the intention-to-treat and per-protocol populations}

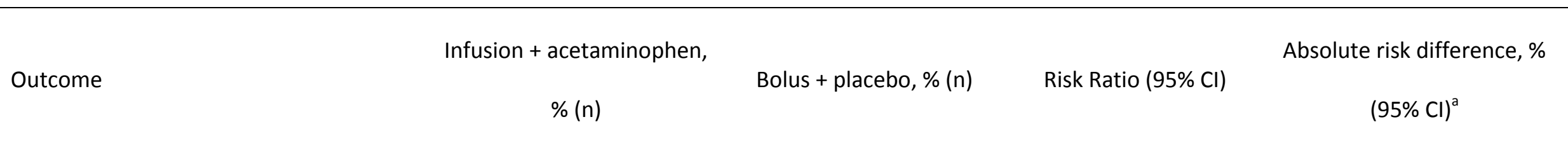

Intention-to-treat

$\begin{array}{lcccc}\text { Day } 7 \text { death } & 32.6 \%(61 / 187) & 34.4 \%(64 / 186) & 0.95(0.71-1.26) & 1.8(-7.8-11.4) \\ \text { Death at discharge } & 38.0 \%(71 / 187) & 40.3 \%(75 / 186) & 0.94(0.73-1.21) & 2.3(-7.6-12.2) \\ \text { SeNeSe or death, day } 7 & 46.5 \%(80 / 172) & 43.4 \%(75 / 173) & 1.07(0.85-1.36) & 3.1(-7.4-13.6) \\ \text { SeNeSe or death, at discharge } & 48.4 \%(90 / 186) & 46.4 \%(85 / 183) & 1.04(0.84-1.29) & 2.0(-8.2-12.2) \\ \text { AnNeSe or death, day } 7 & 57.8 \%(96 / 166) & 51.2 \%(86 / 168) & 1.13(0.93-1.38) & 6.6(-4.1-17.3) \\ \text { AnNeSe or death, at discharge } & 57.5 \%(104 / 181) & 49.7 \%(89 / 179) & 1.16(0.95-1.40) & 7.8(-2.5-18.1)\end{array}$

Per-protocol

Day 7 death

Death at discharge

SeNeSe or death, day 7
$30.6 \%(33 / 108)$

$33.3 \%(36 / 108)$

$40.6 \%(41 / 101)$
$34.4 \%(33 / 96)$

$37.5 \%(36 / 96)$

$44.8 \%(39 / 87)$
$0.89(0.60-1.32)$

$0.89(0.61-1.29)$

$0.91(0.65-1.26)$
$3.8(-9.1-16.7)$

$4.2(-8.9-17.3)$

$4.2(-10.0-18.4)$ 
SeNeSe or death, at discharge

AnNeSe or death, day 7

AnNeSe or death, at discharge
$42.6 \%(46 / 108)$

$53.1 \%(51 / 96)$

$50.0 \%(52 / 104)$
$45.2 \%(42 / 93)$

$54.8 \%(46 / 84)$

$50.6 \%(45 / 89)$
$0.94(0.69-1.29)$

$0.97(0.74-1.27)$

$0.99(0.75-1.31)$
$2.6(-11.2-16.4)$

$1.7(-12.9-16.3)$

$0.6(-13.6-14.8)$

${ }^{\mathrm{a}}$ The absolute risk difference and its confidence intervals were obtained using a 2-sample z-test.

Abbreviations: SeNeSe, severe neurological sequelae; AnNeSe, any neurological sequelae 


$\begin{array}{lcccc} & \text { Bolus }+ & \text { Infusion }+ & & \\ \text { Variable } & \text { placebo, } \% & \text { acetaminophen, } \% & \text { Subgroup- } & \text { Test for } \\ & (n) & (n) & \text { specific } & \text { interaction } \\ & & & P^{\text {a }} & P^{\text {b }} \\ \text { Age } & 33 \%(18 / 54) & 34 \%(18 / 53) & 0.95 & \\ \text { Age }<12 \text { months }(n=107) & 35 \%(46 / 132) & 32 \%(42 / 133) & 0.57 & 0.72 \\ \text { Age } \geq 12 \text { months }(n=265) & & & & \end{array}$

Presenting condition ${ }^{c}$

GCS $<12(n=178)$

$49 \%(46 / 94) \quad 49 \%(41 / 84)$

0.99

$\operatorname{GCS} \geq 12(n=181)$

$20 \%(17 / 87) \quad 17 \%(16 / 94)$

0.74

0.66

Duration of illness before hospital admission ${ }^{d}$

\begin{tabular}{|c|c|c|c|}
\hline $\mathrm{III} \leq 3$ days $(\mathrm{n}=113)$ & $22 \%(14 / 65)$ & $19 \%(9 / 48)$ & 0.72 \\
\hline$\| I I>3$ days $(n=252)$ & $41 \%(47 / 116)$ & $38 \%(51 / 136)$ & 0.62 \\
\hline
\end{tabular}

Weight-for-age Z-score ${ }^{\mathrm{e}}$

Slightly malnourished or normal $(\geq$

$-2 \mathrm{SD})(\mathrm{n}=275)$

$31 \%(43 / 137) \quad 29 \%(40 / 138) \quad 0.66$

Severely malnourished $(<-2$ SD) ( $n$

=96)

$$
42 \%(20 / 48) \quad 42 \%(20 / 48) \quad 1.00
$$

Bacterial etiology

$\begin{array}{llccc}\text { Streptococcus pneumoniae }(\mathrm{n}=73) & 45 \%(17 / 38) & 34 \%(12 / 35) & 0.36 & 0.40 \\ \text { Non-pneumococcal or unknown }(\mathrm{n} \quad 32 \%(47 / 148) & 32 \%(49 / 152) & 0.93 & \end{array}$


$=300)$

These subgroup analyses were predefined, and conducted within the intention-to-treat population.

${ }^{a}$ Obtained using a chi-squared test within the subgroup

${ }^{\mathrm{b}}$ Calculated, using logistic regression analysis, for interaction between each variable and the treatment

${ }^{c}$ Data on the GCS score was missing from 14 participants

${ }^{\mathrm{d}}$ Duration of illness unknown in 8 participants

${ }^{\mathrm{e}}$ Information missing from 2 participants

Abbreviations: GCS, Glasgow Coma Scale score 


\begin{tabular}{|c|c|c|c|}
\hline Variable & $\begin{array}{l}\text { Bolus + } \\
\text { placebo }\end{array}$ & $\begin{array}{l}\text { Infusion + } \\
\text { acetaminophen }\end{array}$ & $P^{a}$ \\
\hline Duration of fever (days) & $2(1-3)$ & $2(1-3)$ & 1.00 \\
\hline Duration of GCS < 15 (days) & $3(1-5)$ & $2(1-5)$ & 0.45 \\
\hline Seizures & $\begin{array}{c}130 / 185 \\
(70 \%)\end{array}$ & $123 / 185(67 \%)$ & 0.43 \\
\hline Focal neurological signs & 76 / 181 (42\%) & 79 / 175 (45\%) & 0.55 \\
\hline $\begin{array}{l}\text { Duration of survivors' hospital stay } \\
\text { (days) }\end{array}$ & $12(10-17)$ & $14(10-20)$ & 0.14 \\
\hline Non-study treatments given & & & \\
\hline Supplementary oxygen & 76 / 186 (41\%) & 76 / $186(41 \%)$ & 1.00 \\
\hline Blood transfusion & 44 / $186(24 \%)$ & 47 / 187 (25\%) & 0.74 \\
\hline Anticonvulsive medication & 89 / 185 (48\%) & 87 / $186(47 \%)$ & 0.80 \\
\hline Malaria treatment & 92 / 186 (50\%) & 90 / 187 (48\%) & 0.80 \\
\hline Ibuprofen, during first four days & $71 / 185(38 \%)$ & 49 / 187 (26\%) & 0.01 \\
\hline $\begin{array}{l}\text { Additional antibiotic treatment } \\
\text { (after first seven days) }\end{array}$ & 70 / $184(38 \%)$ & 79 / $186(43 \%)$ & 0.39 \\
\hline Tuberculosis treatment & $11 / 185(6 \%)$ & 15 / 187 (8\%) & 0.43 \\
\hline
\end{tabular}

Data are displayed as number of patients (\%) or median value (IQR).

abtained using chi-square test or Mann-Whitney U test, as appropriate

Abbreviations: GCS, Glasgow Coma Scale score 


\section{FIGURE LEGENDS}

Figure 1. Flowchart of patient inclusion

Figure 2. Mortality curves for intention-to-treat $(A)$ and per-protocol (B) populations, shown for the first 7 days. Ticks indicate censored participants. 
Figure_1

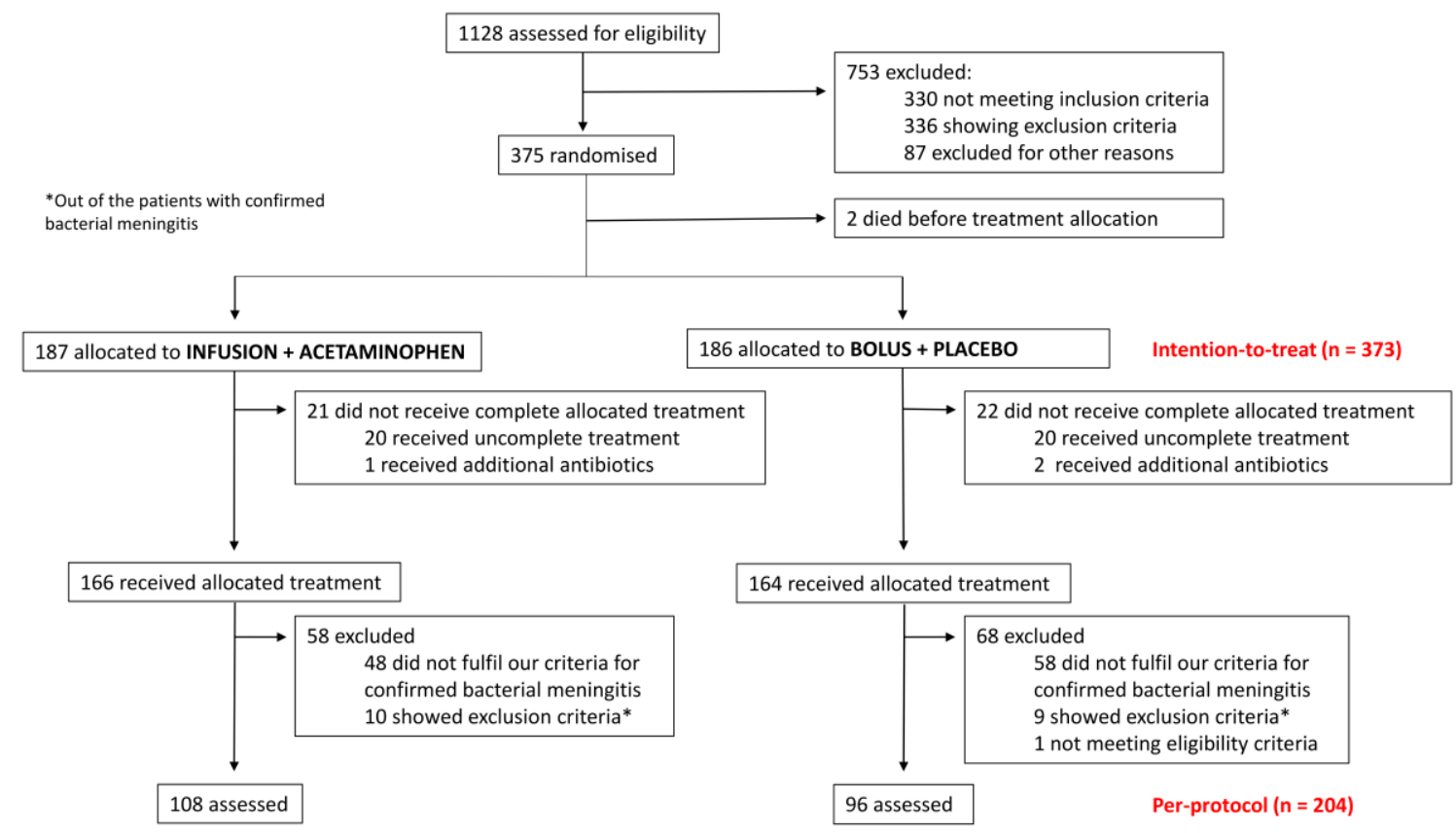


Figure_2

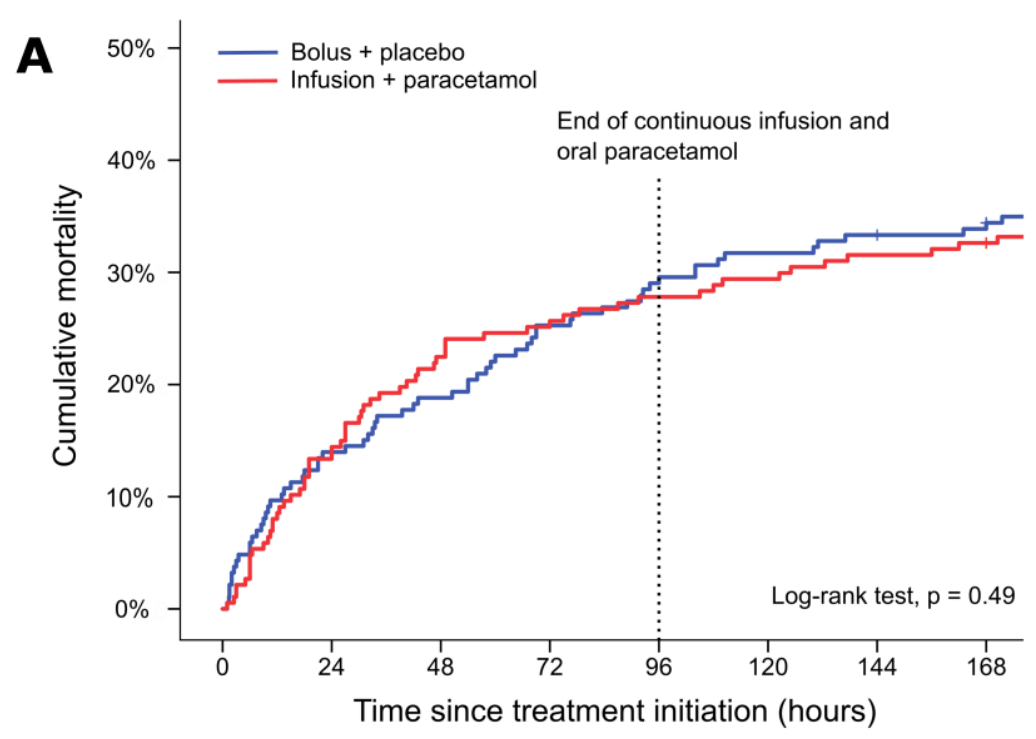

$\begin{array}{lrrrrrrrr}\text { Number } & 186 & 160 & 151 & 139 & 131 & 127 & 123 & 119 \\ \text { at risk } & 187 & 160 & 145 & 139 & 135 & 132 & 128 & 123\end{array}$

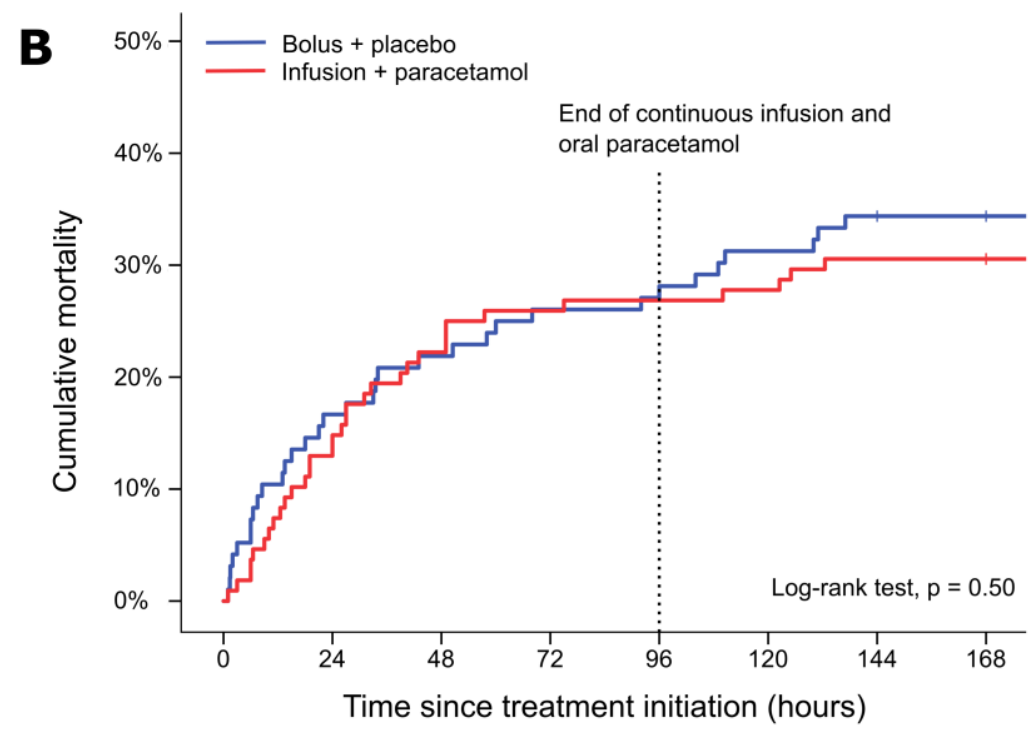

$\begin{array}{lllllllll}\text { Number } & 96 & 80 & 75 & 71 & 69 & 66 & 62 & 61 \\ \text { at risk } & 108 & 92 & 84 & 80 & 79 & 78 & 75 & 72\end{array}$

